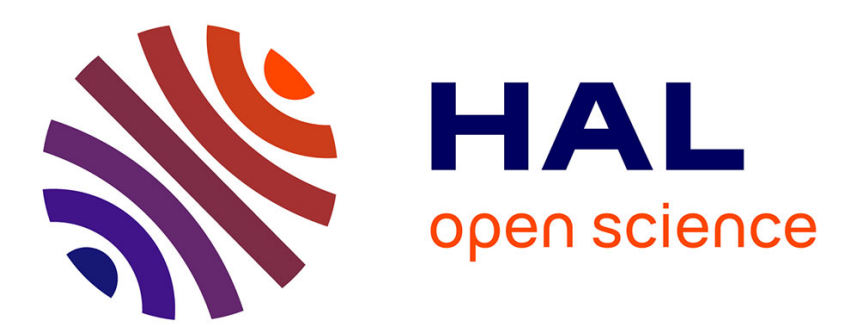

\title{
Experimental study of the bubble formation in T-Y junction micro-mixers
}

Nicolas Dietrich, Souhila Poncin, Huai-Zhi Li

\section{To cite this version:}

Nicolas Dietrich, Souhila Poncin, Huai-Zhi Li. Experimental study of the bubble formation in T-Y junction micro-mixers. La Houille Blanche - Revue internationale de l'eau, 2011, 4 (4), pp.62-69. 10.1051/lhb/2011042 . hal-00778251

\section{HAL Id: hal-00778251 \\ https://hal.science/hal-00778251}

Submitted on 11 Jul 2021

HAL is a multi-disciplinary open access archive for the deposit and dissemination of scientific research documents, whether they are published or not. The documents may come from teaching and research institutions in France or abroad, or from public or private research centers.
L'archive ouverte pluridisciplinaire HAL, est destinée au dépôt et à la diffusion de documents scientifiques de niveau recherche, publiés ou non, émanant des établissements d'enseignement et de recherche français ou étrangers, des laboratoires publics ou privés. 
Experimental study of the bubble formation in T-Y junction micro-mixers

\title{
N. Dietrich ${ }^{1,2,3,4,{ }^{*}, \text { S. Poncin }}{ }^{1}$ and Huai Z. $L I^{1}$
}

1 : Nancy Université, Laboratoire Réactions et Génie des Procédés, CNRS-ENSIC, 1 rue Grandville, BP 20451, 54000 Nancy Cedex, France.

2: Université de Toulouse; INSA,UPS,INP; LISBP, 135 Avenue de Rangueil, F-31077 Toulouse, France

3 : INRA, UMR792, Ingénierie des Systèmes Biologiques et des Procédés, F-31400 Toulouse, France

4 : CNRS, UMR5504, F-31400 Toulouse, France

* To whom correspondence should be addressed.

Tel.: +33(0)3 83175367 - Fax.: +33 (0)3 83595796 - E-mail: dietrich@ensic.inpl-nancy.fr

Keywords : bubble, micro-devices, correlation, micro-PIV, gas-liquid

\begin{abstract}
The aim of this study is to investigate the bubble formation in different liquids within three types of gas-liquid micro-mixer geometries, including a T-junction and two Y-junctions. The bubble shape, size and formation mechanism were studied under various experimental conditions such as flow rates of both phases, physical properties of liquid and mixer's geometries. A micro-Particle Image Velocimetry ( $\mu$-PIV) technique and a high speed camera were used to characterize and quantify gas-liquid flows. It was revealed that the bubble formation, in particular the bubble size, depends on the geometry of the mixing section. A correlation gathering numerous experimental data was elaborated for the estimation of bubble size. The influence of different parameters like flow rate ratio between two phases, mixer geometry and surface tension is well taken into consideration based on the understanding of bubble formation mechanism at microscale. This paper marks an improvement in the domain where no global correlations were available in $\mathrm{T}$ and $\mathrm{Y}$-junction devices, and this correlation is then an useful tool for micro-mixer design.
\end{abstract}

\section{Introduction}

Multiphase flows in microfluidic devices have recently received much attention because of the foreseeable advantages that unique microscale properties can offer such as enhancement of heat and mass transfer efficiency, reduced axial dispersion and smaller sample volumes. In order to quantify these benefits, a good understanding of the complex multiphase flow behavior in microfluidic devices must be gained. In particular, the formation of bubbles finds very wide applications such as the generation of biogas bubbles by anaerobic sludge granules in a bioreactor [1, reference Jess], bubble nucleation in polymer devolatization processes [2], two-phase micro-mixing [3], fluorinations [4], hydrogenations [5], biochemical reactions such as DNA analysis [6], materials synthesis [7, 8], ultrasonic imaging [9, 10], lipid encapsulation [11] and drug discovery [12].

The two-phase flow patterns in microchannels are determined by the flow conditions, the channel geometry and the properties of both fluids involved. Generally, the gas-liquid flow in microchannels can be classified into five different regimes, namely, the bubbly flow, the slug flow, the slug stratified flow, the stratified flow and the spray flow [13]. The bubbly flow is 
characterized by the formation of single spherical bubbles with bubble lengths smaller than, or equal to the channel width. Increasing the gas flow rate causes the coalescence of small bubbles leading to cylindrical bubbles (separated from the wall by a very thin film); this regime is known as slug flow and also as plug, bubble-train, or Taylor flow. Thereafter, slugstratified flow develops, in which waves are formed from the film that are not large enough to fill the entire channel diameter. A supplementary increase in the gas flow rate leads to the stratified flow regime. When the gas flow rate is further increased, the spray flow takes place, which consists of very small liquid droplets in a continuous gas phase. This flow regime map has been developed by several authors [14, 15], usually as a function of the superficial velocities of the gas and liquid phases. Finally, bubbly flow appears at high liquid flow rates and low gas velocities and slug flow occurs at intermediate gas and liquid velocities. In the present study, experiments were mainly focused on the segmented gas-liquid flows, i.e., bubbly and slug regimes, and laminar flow regime for liquid phase.

The most popular geometries for the generation of dispersed phases are T-junctions $[3,16,17$, $18,19,20,21]$ and flow-focusing devices $[14,22,23,24]$. There are two preparation methods for junction devices. The first is lithographically prepared devices and the second is a Tjunction which can be put together by connecting capillaries. Both these devices are covered by this work. In these devices, the bubble formation was governed by the pressure gradient and the breakup could be controlled by the flow rate of the continuous liquid phase and could be attributed to a competition between the pressures in gas and liquid phases $[14,24]$.

Recently, liquid flow fields in microfluidic devices have been investigated by means of micro-Particle Image Velocimetry ( $\mu$-PIV) technique. For example, single-phase flows in microfluidic T-junctions [26, 27], simple co-flowing micro-channel [28] were characterized by $\mu$-PIV technique. Theses $\mu$-PIV measurements show that the bubble formation is due to the velocity component normal to the gas flow created by the sudden change of the liquid velocity distribution around the channel frontier. It is worth noting that up to now, there are still very few $\mu$-PIV studies devoted to the flow fields around a bubble in formation in such devices. Velocity fields obtained by $\mu$-PIV have been reported for the bubble formation in a T-junction [29], in a Y-junction [30] and in flow focusing microdevice [31].

For many industrial applications, it is essential to be able to establish the relationship between the geometric features and the flow pattern such as bubble and slug length. Some correlations were proposed to characterise the formation of bubbles (length or volume) for jet flow [32]; for a cross flow-focusing mixer $[3,23,24,31]$. These relationships link the bubble length and the flow rate ratios but with a limited precision on these parameters.

In the literature, there are only a few studies on the effect of the micro-mixer geometry [15, 33]. They reported that the breakup by pressure gradient was only observed in the T-type mixer, while the jet instability was the unique mechanism for bubble formation in the Yjunction. The bubble shape and size and the formation mechanism were also considered for different flow rates. Theses authors compared satisfactorily the simulated results with experimental data in the form of dimensionless numbers [33]. Different flow regimes with different bubble shapes were found depending on the capillary number. The simulated data confirmed that the breakup was induced by the pressure difference in both phases. The geometry of the mixing section was also observed to have an impact on the size of the gas and liquid slugs. Recently, the section geometry for flow focusing microdevice was studied and a correlation proposed [31] to design these reactor, but this kind of tools is still missing for $\mathrm{T}$ and $\mathrm{Y}$-junction microdevices. 
The present work is devoted to the formation of bubbles in $\mathrm{T}$ and $\mathrm{Y}$-junction micro-mixers of different geometries. By means of a $\mu$-PIV system and a high speed digital camera, the role of inertial, viscous and interfacial forces was experimentally investigated to gain new insight into the mechanism of bubble formation at micro-scale in order to develop a correlation making smooth micro-reactor design for gas-liquid application.

\section{Experimental setup}

The different geometries of micro-mixers used in this study are shown in Figure 1. The microchannels were fabricated in polymethyl methacrylate (PMMA). The mixers' geometry had two channel inlets, one for the continuous liquid phase and another for the dispersed gas phase flow. Three different sizes of channels were $500 \mu \mathrm{m}, 800$ and $1000 \mu \mathrm{m}$. The channels sections were square to facilitate the visualisation of the flow field.
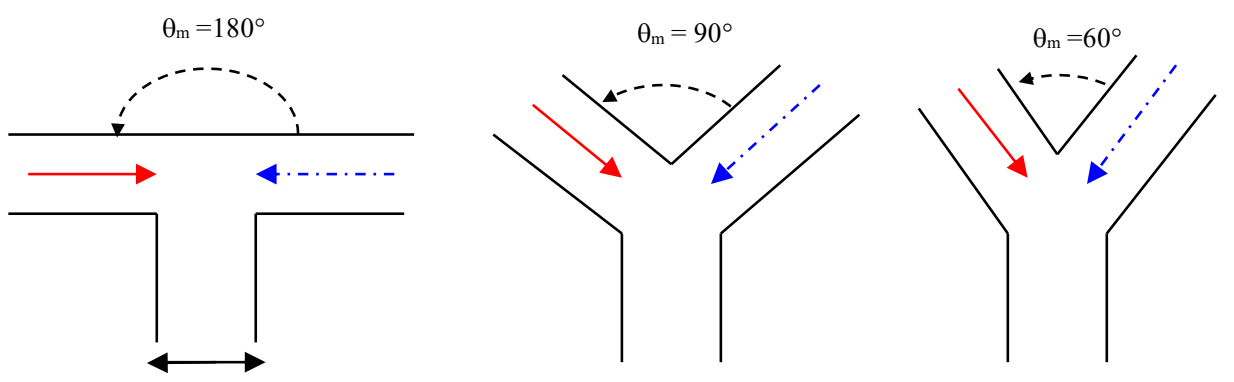

Gas flow

$\mathrm{W} \in[500 ; 800,1000 \mu \mathrm{m}]$

Figure 1. Illustration of the microfluidic devices used to generate micro-bubbles. From the left to the right, $\mathrm{T}$-junction $\left(180^{\circ}\right)$, Y-junction $\left(90^{\circ}\right.$ and $\left.60^{\circ}\right)$.

Two pressurized tanks of $10^{-3} \mathrm{~m}^{3}$ were used to maintain a constant pressure and to push the liquid and air streams into the micro-channels with a regular flow rate for each phase. A gas flow-meter was employed to determine the flow rate with precision. Images of bubbles were captured by a high speed digital camera CamRecord600 (Optronis GMBH, Germany) equipped with a microscopic objective ranging from $\times 100$ to $\times 600$. The typical acquisition rate was 500 frames per second with a full resolution of $1280 \times 1024$. Under the steady formation conditions, the length of the bubble was determined through an image analysis software and the bubble volume $V_{b}$ was calculated from the gas flow rate $Q_{g}$ and the bubble formation frequency $f$ determined by the high speed camera as follows:

$$
V_{b}=\frac{Q_{g}}{f} \quad \text { (1) }
$$

The instantaneous liquid velocity flow fields were measured by a $\mu$-PIV system (Dantec Dynamics, Denmark). The system consists of a Flowsense Dantec Camera with a 2048×2048 pixel array and a $7 \mathrm{~Hz}$ frequency. The inversed microscope (Leica DM ILM) was equipped with different objectives (Leica HC PLAN) ranging from $\times 5$ to $\times 100$. The microdevice under investigation faced the microscope and was illuminated from the back by a micro-strobe emitting a light at $530 \times 10^{-9} \mathrm{~m}$ (the monochromatic character avoids the chromatic aberrations in the imaging analysis). 

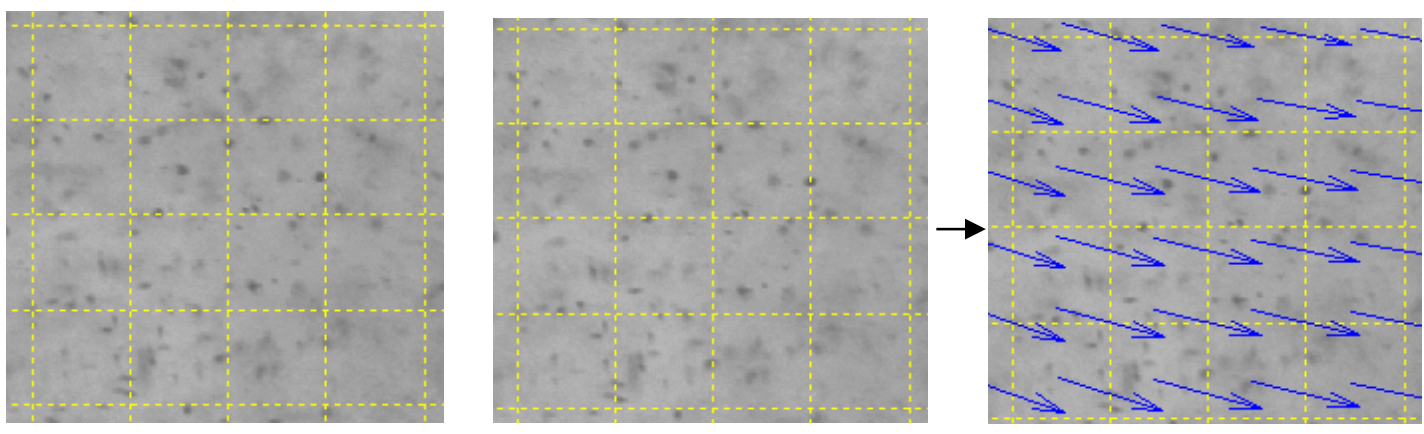

Figure 2. Micro Particle Image Velocimetry principle ( $\mu$-PIV). $50 \times 50 \mu \mathrm{m}$ windows.

The liquid velocity fields were measured by tracking and evaluating the motion of seeding particles suspended in the fluid. The principle of $\mu$-PIV is reported in Figure 2. The camera took two successive images at the maximum intensity of the micro stroboscope impulse. The acquired images of the flow were analysed by dividing the images into a few thousands of small areas of $16 \times 16$ pixels called interrogation areas. A cross-correlation was then applied on the interrogation areas in consecutive images with a 50\% window overlap. For each interrogation area, the displacement vector was calculated from the location of the correlation peak. The velocity fields were then computed from the displacement vectors and the time interval between the images. The measurements were realized on a slice of the micro-mixer of a value around $10 \mu \mathrm{m}$ due to the focus of the microscope. However, this value is negligible in comparison with the thickness of the microchannel. Seeding particles should be uniformly dispersed in fluid with a reasonable concentration. The density should be similar to that of studied fluid. If the seeding particles used are too small, the Brownian motion could induce errors in measurements. This random motion sets a lowest limit of seeding particles' size to achieve $\mu$-PIV measurements. Starting from the equation of Einstein-Sutherland [34], it is possible to estimate the influence of this Brownian [35] motion through a diffusion coefficients $D$ :

$$
D=\frac{k T}{6 \pi \mu r}
$$

$T$ is the temperature, $\mu$ fluid viscosity, $r$ particle radius and $k$ the Boltzmann constant. This equation shows that the Brownian motion depends inversely on the radius of the particle. The standard deviation of the random movement of a particle is given by:

$$
\Sigma_{p}=\Delta x_{p} \approx \sqrt{2 D \delta t}
$$

Thus, for a camera frequency of $4 \mathrm{~s}^{-1}$ and a particle diameter of $200 \times 10^{-9} \mathrm{~m}$, the random movement is estimated at $3 \times 10^{-6} \mathrm{~m} \cdot \mathrm{s}^{-1}$. The liquid velocity used in this study being several hundreds micrometers per second, an error of order of percent is then expected for the velocity. Larger particles should be chosen to avoid inaccuracy problems due to the Brownian motion. But bigger the particle is, higher is its settling velocity. The sedimentation velocity of a particle of diameter $d$ is estimated in the Stokes' regime

$$
v_{p}=\frac{d^{2} g\left(\rho_{p}-\rho_{l}\right)}{18 \mu}
$$

For seeding particles of $3 \times 10^{-6} \mathrm{~m}$ diameter, the value of the sedimentation velocity is around $1.5 \times 10^{-6} \mathrm{~m} . \mathrm{s}^{-1}$. Finally, to reach a suitable compromise between the Brownian motion and settling velocity for which the relative error is below $1 \%$, the optimal size of seeding particle has to be in the range $\left[0.5-3 \times 10^{-6} \mathrm{~m}\right]$. Furthermore, the size of the geometry, viewing windows and camera objectives help to refine the value of the particle diameter. In this study, 
hydrophilic latex microspheres (Merck Estapor, France) with a density of $1056 \mathrm{~kg} . \mathrm{m}^{-3}$ and a mean calibrated diameter of $0.88 \times 10^{-6} \mathrm{~m}$ were used as seeding particles. These particles were small enough to follow the fluid and large enough to avoid the Brownian motion effects. When the flow is correctly inseminated ( 5 particles per interrogation area, ie $10^{11}$ to $10^{13}$ particles $/ \mathrm{m}^{3}$ ), the measurement errors of the measured velocities are less than $5 \%$.

In this work, the experiments were performed using air as gas phase and three different liquids (pure water, viscous Newtonian Emkarox HV45 10\% and 20\% wt dilute solutions in demineralised water). A Rheometric Fluid Spectrometer RFS II (Rheometric Scientific) was employed to characterize the rheological properties of the liquids (Table 1). The surface tension and the contact angle of the liquid on the PMMA surface were measured using a tensiometer, by the pending drop technique on a Tracker apparatus (I.T. Concept, France). Sodium Dodecyl Sulphate surfactant (SDS, Amersco, USA) was also used to modify the surface tension, which allows to compare separately the effect of surface tension and viscous force. Table 1 gathers the properties of various liquids used. All experiments were carried out at a constant temperature of $293 \mathrm{~K}$.

Table 1. Properties of the different liquids used in this study at $293 \mathrm{~K}$.

\begin{tabular}{l|c|c|c|c}
\hline \multicolumn{1}{c|}{ Fluid } & $\rho\left(\mathrm{kg} . \mathrm{m}^{-3}\right)$ & $\mu\left(\times 10^{3} \mathrm{Pa.s}\right)$ & $\theta_{\text {contact }}$ & $\sigma\left(\times 10^{3} \mathrm{~N}_{\mathrm{m}}^{-1}\right)$ \\
\hline Water & 1000 & 1 & $66^{\circ}$ & 72 \\
Water + 0.10\% SDS (wt) & 1000 & 1 & $64^{\circ}$ & 50 \\
Water + 0.15\% SDS (wt) & 1000 & 1 & $61^{\circ}$ & 40 \\
\hline HV45 10\% (wt) & 1030 & 10 & $56^{\circ}$ & 50 \\
HV45 10\% (wt) + 0.05\% SDS (wt) & 1030 & 10 & $52^{\circ}$ & 40 \\
\hline HV45 25\% (wt) & 1050 & 30 & $47^{\circ}$ & 40
\end{tabular}

\section{Experimental results}

In the present work, extensive experimental investigation was realized for the bubble formation in three different micro-mixer geometries of various junction angles (180, 90 and $60^{\circ}$ ). In order to understand the key parameter of the bubble formation process, a preliminary study was devoted to the influence of main parameters.

The gas and liquid flow rates ranged from $10^{-12} \mathrm{~m}^{3} \cdot \mathrm{s}^{-1}$ to $10^{-6} \mathrm{~m}^{3} \cdot \mathrm{s}^{-1}$, which corresponds to the bubbly and slug flow regimes and bubble diameters between $50 \times 10^{-6} \mathrm{~m}$ and $5 \times 10^{-3} \mathrm{~m}$. The bubble formation was studied by both $\mu$-PIV and high speed camera visualization. The shape evolution of a $10^{-9} \mathrm{~m}^{3}$ bubble in time during the formation process until its detachment is shown in Fig. 3. The bubble formation was perfectly periodic with a frequency of $30 \mathrm{~s}^{-1}$. Figure 3 shows the growth process during one period.

The bubble shape was issued from the image analysis by means of a high speed camera. One can distinguish two steps during the formation of the bubble: firstly, a fast expansion of the growing bubble; secondly, a slow elongation of the bubble until to the thread rupture. 


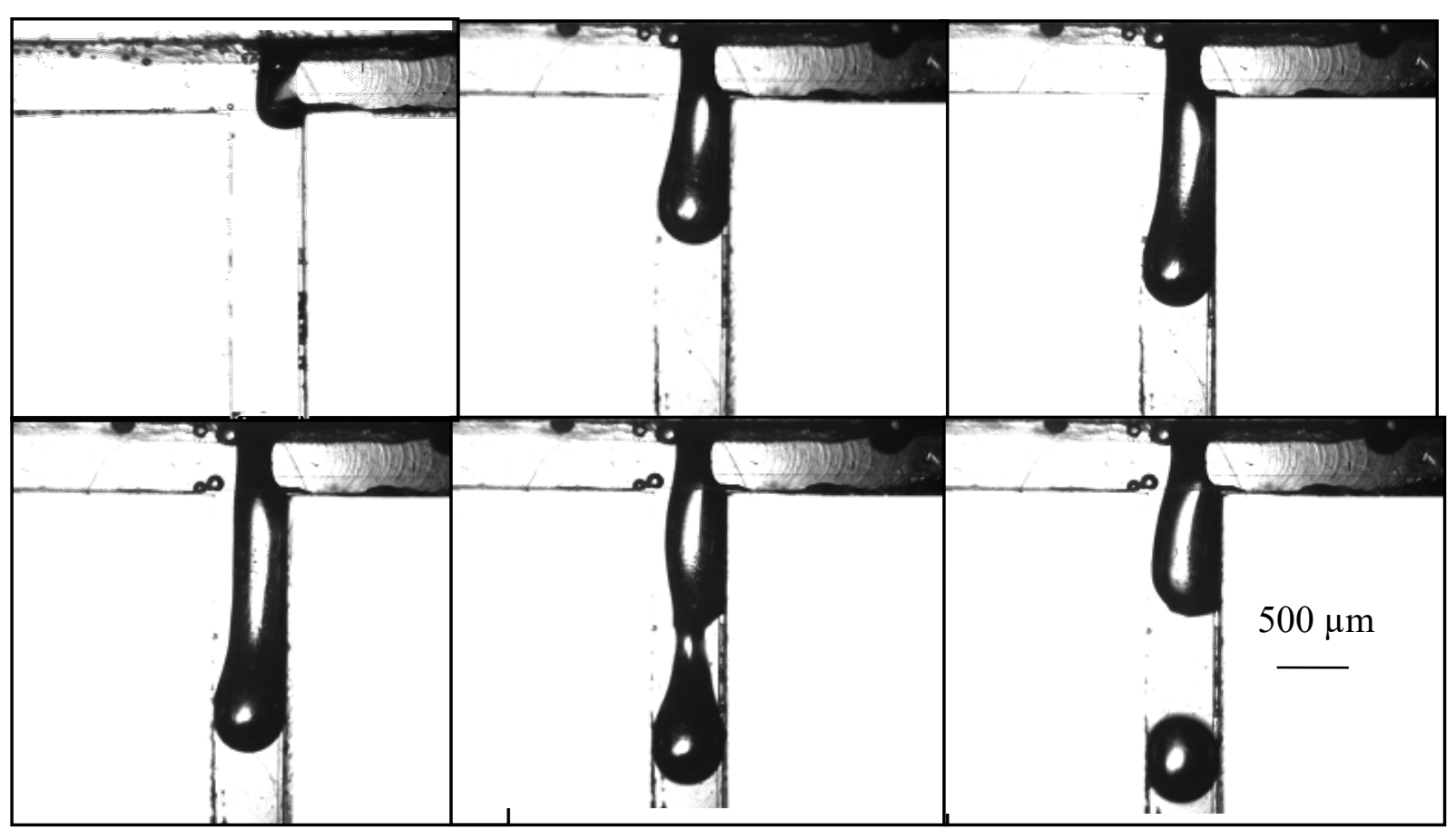

Figure 3. Bubble formation in a T-junction. $\mathrm{V}_{\mathrm{b}}=0.8 \times 10^{-9} \mathrm{~m}^{3}$. Channel size $500 \mu \mathrm{m}$, pure water as liquid, liquid and gas flow rate: $10^{-8} \mathrm{~m}^{3} \cdot \mathrm{s}^{-1}$.

Contrary to flow-focusing devices [32, 34], where the formation always occur in the middle of the micro-mixers junction, in $\mathrm{T}$ and Y-junction, the breakup occurs in the outlet channel and the influence of the junction geometry is significant. Figure 4 illustrates the comparison of the formation of a $10^{-9} \mathrm{~m}^{3}$ bubble in two different junction geometries. In the case of the bigger angle, the bubble spreads largely on the channel wall.

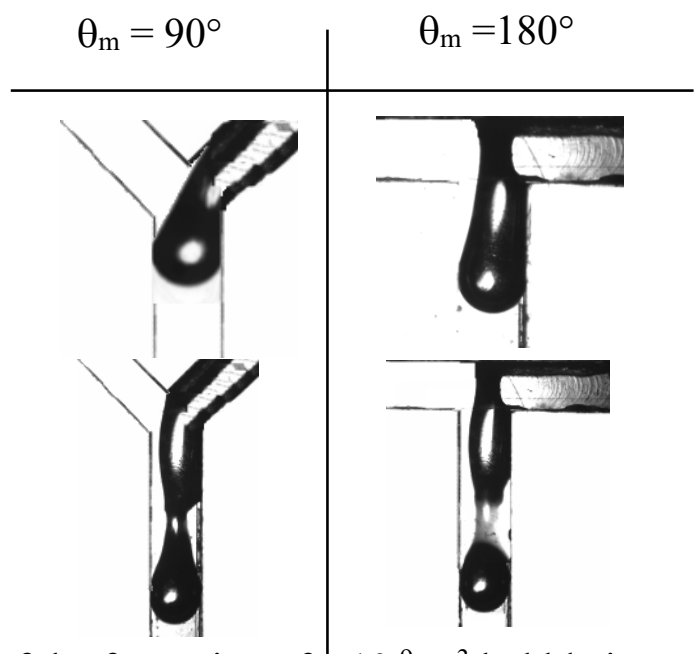

Figure 4. Comparison of the formation of $10^{-9} \mathrm{~m}^{3}$ bubble in two different junction geometries.

Fig. 5 shows the liquid velocity fields around a forming gas bubble in a Y-junction. The bubble formation can be divided into three steps. The obtained flow fields during these steps give different quantitative information. The length and the orientation of the arrows enable to understand the phenomena leading to the rupture of the gas neck. 


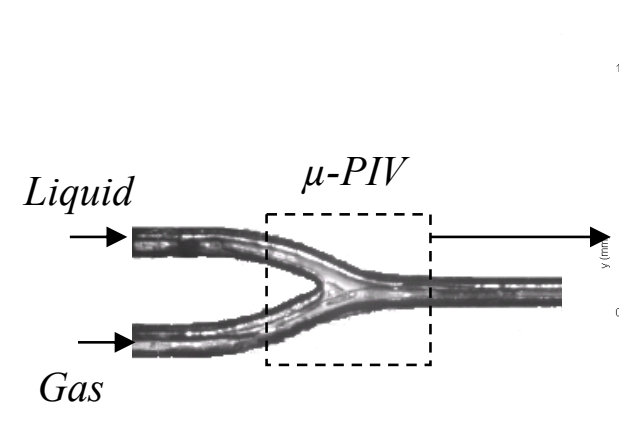

$(5 b)$

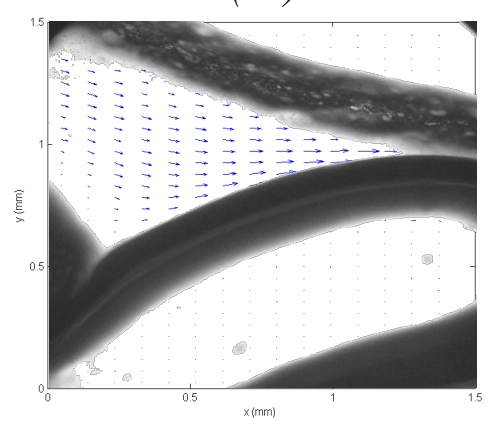

$(5 a)$

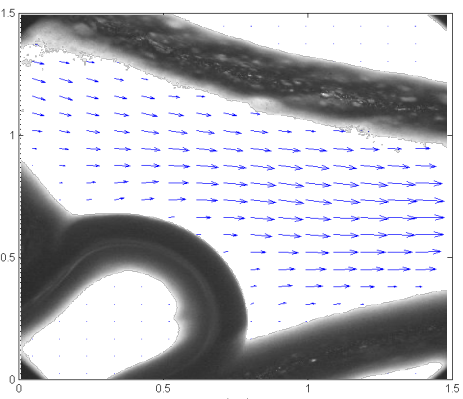

$(5 c)$

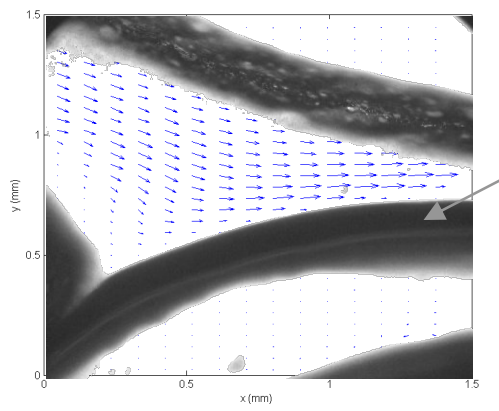

Rupture of the bubble

Figure 5. Velocity Flow fields around a forming air bubble in a $\mathrm{Y}$-junction of $800 \mu \mathrm{m}$ in water $+0.15 \%$ (wt) SDS, $\mathrm{Q}_{1}=10^{-7} \mathrm{~m}^{3} / \mathrm{s}\left(\mathrm{v}_{1}=0.2 \mathrm{~m} / \mathrm{s}\right), \sigma=40 \mathrm{mN} / \mathrm{m}$.

Firstly, Fig. 5a corresponds to the arrival of the gas phase in the outlet channel of the junction. The corresponding flow fields show that the liquid phase pushes the gas towards the flow direction, causing the elongation of the gas phase. The second step, shown in Fig. 5b, concerns the elongation of the film and, at the same time, the shearing by the liquid phase described by the flow gradients. These dual shearing and elongation actions make the formation of a gas bubble possible as represented in Fig. 5c.

The $\mu$-PIV technique is a powerful tool to evaluate the main forces acting on the bubble. As shown in Fig. 5, the neck interface of the bubble undergoes the deformation under shear stresses which could be estimated from the liquid flow gradients at the interface of the bubble. For example, the mean shear rate is about $500 \mathrm{~s}^{-1}$ in Fig. 5. By comparison with other forces acting on the bubble, the shear stress is not the key force [3, 24, 31]. The main formation mechanism depends on the competition between the static pressure and surface tension. The measurement of the flow field around a forming bubble in a $\mathrm{T}$ or $\mathrm{Y}$-junctions makes possible the evaluation of both the viscosity and surface tension forces [36]. A simple balance of pressure drop at bubble pinch-off leads to the estimation of the surface tension force $\left(\mathrm{V}_{\mathrm{L}}=\right.$ $0.79 \mathrm{~m} / \mathrm{s}$ and $\left.\mathrm{R}_{\mathrm{b}}=250 \mu \mathrm{m}\right)$.

$$
\Delta P=\frac{1}{2} \rho v^{2}=\frac{2 \sigma}{R_{B}} \Rightarrow \sigma_{\text {calculated }}=40.5 \mathrm{mN} / \mathrm{m} \approx \sigma_{\text {measured }}
$$

Thus, the $\mu$-PIV technique can permit the magnitude estimation of different forces involved in order to highlight the main parameter controlling the bubble formation.

To illustrate the results obtained by the $\mu$-PIV, the breakup distance from the junction at which rupture takes place $\left(D_{\text {break-up }}\right)$ was shown in Fig. 6 for different gas and liquid flow rates as a function of $Q_{G} / Q_{L}$. 


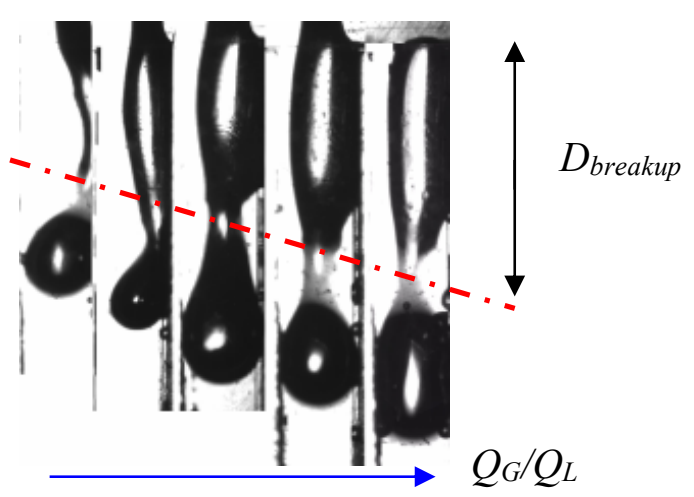

Figure 6. Variation of the distance of breakup in function of flow rates ratio $Q_{G} / Q_{L}$.

For a given gas phase flow rate, $D_{\text {breakup }}$ decreases with the liquid phase flow rate, which stems from the predominance of the shearing effect by the liquid. Moreover, this parameter increases with the gas phase flow rate. A correlation based on 50 experimental data is proposed to show a general tendency with an average error of $9 \%$ :

$$
\frac{D_{\text {breakup }}}{W}=4\left(\frac{Q_{G}}{Q_{L}}\right)^{0.15} \text { (6) }
$$

Thus the flow rate ratio seems to play a key role in the formation of micro-bubbles. A scaling law was searched for quantifying its influence. Fig. 7 illustrates the evolution of the dimensionless ratio $L / W$ of the bubble length to the channel width with the flow rate ratios $Q_{G} / Q_{L}$. The formed bubble volume increases with the gas flow rate, and decreases with the liquid flow rate. This gradual evolution could be explained by the increase of shear stress and elongation with the liquid flow rate. Higher liquid flow rate results in the formation of smaller bubbles.
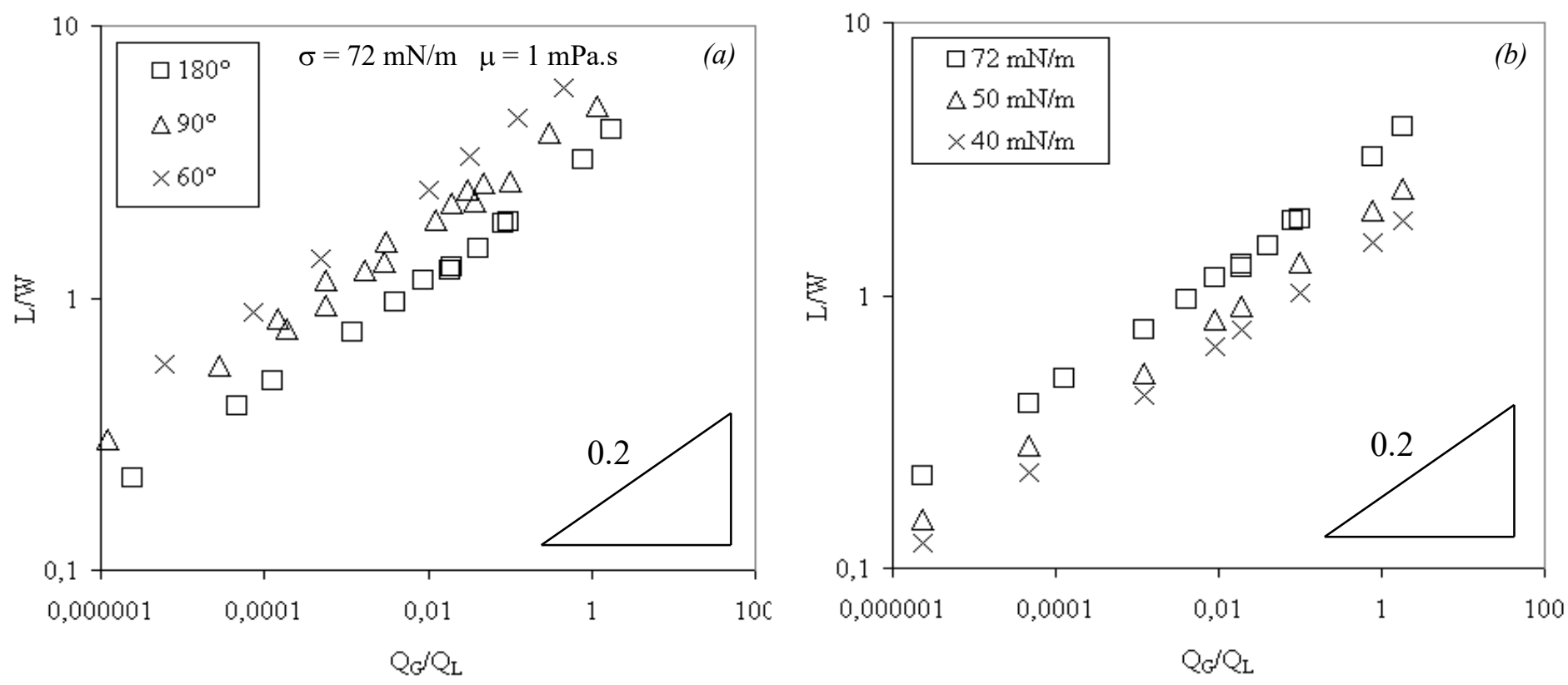

Figure 7. Influence of the liquid properties and junction geometry. Channe size of 500, 800 and $1000 \mu \mathrm{m}$ respectively. (a) Influence of the junction angle $\theta_{\text {mixer }}$. (b) Influence of the surface tension. 
The evolution of $L / W$ ratio as a function of the $Q_{G} / Q_{L}$ ratio for various sizes of the gas inlet and gas-liquid outlet (Fig. 5b) may be represented by the following correlation:

$$
\frac{L}{W}=\beta\left(\frac{Q_{G}}{Q_{L}}\right)^{\alpha}
$$

where both the power law index and constant $\beta$ value depend on the liquid properties and the junction geometry. This simple correlation describes satisfactorily the influence of both the flow rates and the size of the microchannels. The effect of the junction geometry on the bubble length was studied for three types of junctions shown in Fig. 7a: a T-junction for which the liquid inlet channel was perpendicular to the outlet channel. Two other types were the Y-junction with angle of respectively $90^{\circ}$ and $60^{\circ}$ between both gas and liquid inlet channels. The width of these sqaure channels was 500, 800 and $1000 \mu \mathrm{m}$. For a given geometry, the increase of the ratio of gas flow rate to liquid flow rate yields the augmentation of the bubble length. However, the bubble size increases with the decrease of the angle (Fig. 7a). The effect of the surface tension was investigated by the addition of the SDS surfactant in water in the T-junction $\left(180^{\circ}\right)$. As expected, the bubble length increases with the surface tension (Fig. 7b). Finally, the effect of the liquid viscosity was investigated in the T-junction. As reported in the literature $[3,24,29,31]$ the effect of fluid viscosity is quite small.

The factor $\beta$ in Eq. 7 seems to be linked to the two parameters acting on the bubble formation. A dimensional analysis was applied to develop a dimensionless correlation of the bubble length under various operating conditions and junctions' geometry investigated in this study. 110 data points were gathered to determine such a correlation. Table 2 resumes the correlations obtained for each junction geometry.

Table 2. Comparison of the correlations for different junction geometries

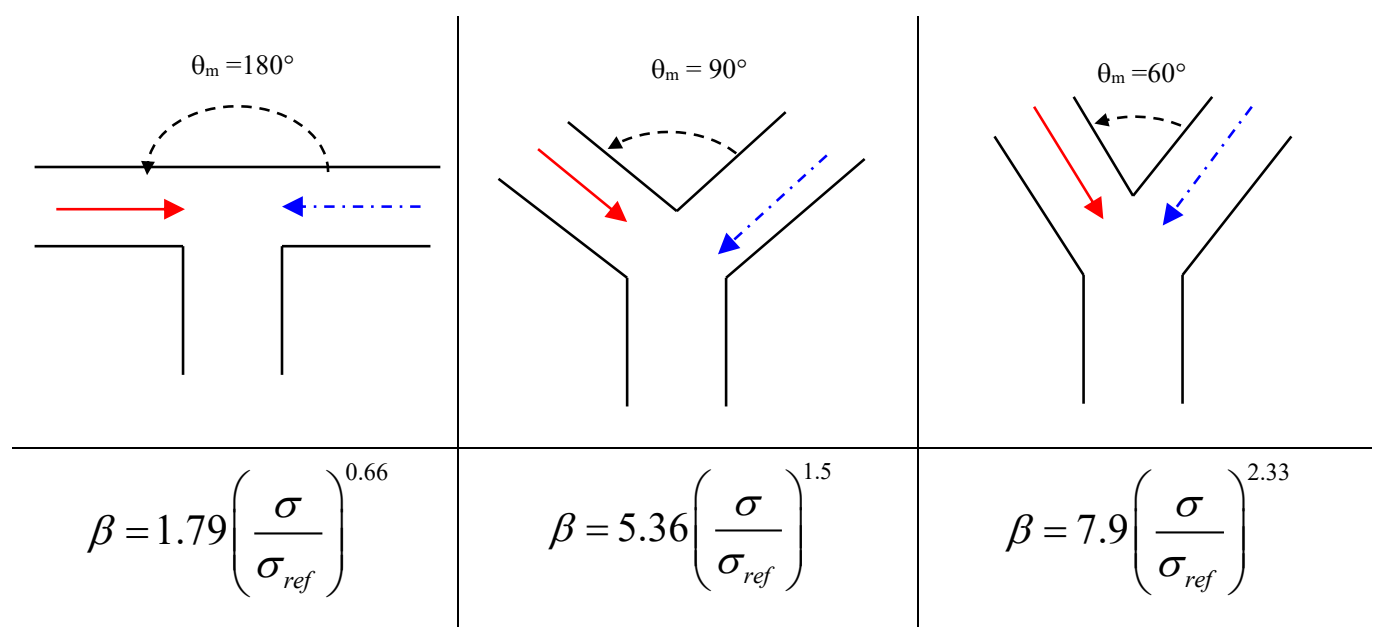

The dimensionless number based on the surface tension was introduced using the value of water in air as a reference $\sigma_{\text {ref. }}$. The experimental data are quite well described by these correlations with an average relative error below $6 \%$.

To quantify different effects of the junction angle, liquid viscosity and surface tension, a dimensionless angle $\theta_{m} / \theta_{\text {ref }}$ was added in the above correlations where $\theta_{\text {ref }}$ is the maximal angle ( $180^{\circ}$ for the $\mathrm{T}$-junction). The following dimensionless correlation was proposed to represent all 110 experimental data: 


$$
\frac{L}{W}=2.5\left(\frac{\theta_{m}}{\theta_{\text {ref }}}\right)^{-0.33}\left(\frac{\sigma}{\sigma_{\text {ref }}}\right)^{1.2}\left(\frac{Q_{\text {gas }}}{Q_{\text {liquid }}}\right)^{0.2}
$$

The average relative error is about $9.5 \%$ with a maximum value of $18.7 \%$. This correlation gives a good estimation for the bubble formation in liquid of viscosity ranging from 1 to 30 $\mathrm{mPa} . \mathrm{s}$, surface tension of 40 to $72.5 \mathrm{mN} / \mathrm{m}$, flow rate ratio ranging from $10^{-6}$ to 100 and different geometries and junction sizes (angle $\theta_{m}$ of 180,90 and $60^{\circ}$ and $W=500,800$ and $1000 \mu \mathrm{m})$. It could be a useful tool for a quick design of micro-mixers under various operating conditions. The similar correlation was established for the bubble volume:

$$
\frac{V_{b}}{W^{3}}=6.87\left(\frac{\theta_{m}}{\theta_{\text {contact }}}\right)^{-0.46}\left(\frac{Q_{\text {gas }}}{Q_{\text {liquid }}}\right)^{0.2} \text { (9) }
$$

Fig. 8 shows a good agreement between the experimental and predicted values $V_{b} / W^{3}$ with an average error of about $12 \%$. In this correlation, the surface tension was replaced by the contact angle $\theta_{\text {contact }}$ of the liquid on the wall material to simplify the use of the correlation.

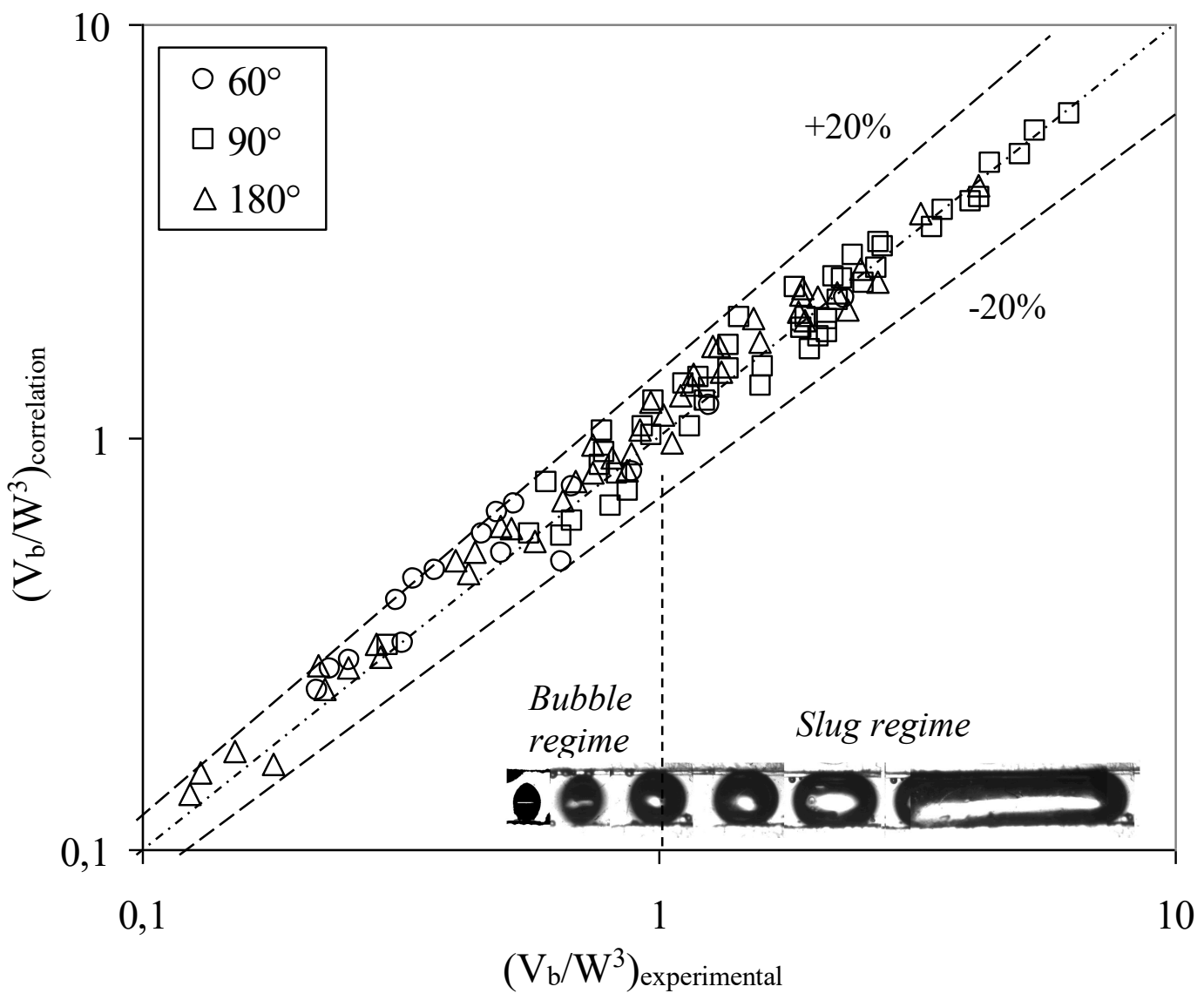

Figure 8. Parity diagram between correlated data and experimental results. 


\section{Conclusion}

The segmented flow of a train of bubbles finds very wide applications in microfluidic devices. In this work, the experiments were carried out to study the gas-liquid flows in microchannels. The bubble shape, size and formation mechanism were investigated under different flow conditions. The current work confirms the general mechanism of bubble formation by means of $\mu$-PIV measurements. The liquid flow fields during the formation of bubbles provide important quantitative details. Moreover, the bubble size was shown dependant on the surface tension as well as the geometries of the junction section. According to the junction's geometry, the surface tension has different effect and that of the liquid viscosity is almost negligible. Finally, some correlations were proposed to estimate the bubble volume and length for different gas-liquid systems and junction geometries investigated. The predicted values are in good agreement with the experimental results and the final correlation proposed is a useful tool for quick micro-reactor design in gas-liquid applications.

Acknowledgements: The financial assistance provided by the French Ministère de l'Enseignement Supérieur et de la Recherche is gratefully acknowledged.

\section{Notation}

$V_{b} \quad$ Bubble volume, $m^{3}$

$W \quad$ Channel width, $m$

$Q \quad$ Flow rate, $m^{3} s^{-1}$

B Bbble length, $m$

$R_{b} \quad$ Bubble radius, $m$

$r \quad$ Radius, $m$

$k \quad$ Boltzmann constant, $J / K$

$D \quad$ Diffusion coefficient, $\mathrm{m}^{2} / \mathrm{s}$

$T$ Temperature, $K$

$v \quad$ Liquid velocity, $\mathrm{m} / \mathrm{s}$

\section{Greek Letters}

$$
\begin{array}{ll}
\dot{\gamma} & \text { Shear rate, } \mathrm{s}^{-1} \\
\Sigma & \text { Standard deviation, } m \\
\alpha, \beta & \text { Power law coefficients } \\
\mu & \text { Liquid viscosity, Pa.s } \\
\theta & \text { Angle, }{ }^{\circ} \\
\rho & \text { Density, } \mathrm{kg} . \mathrm{m}^{-3} \\
\sigma & \text { Surface tension, }{\mathrm{N} . \mathrm{m}^{-1}}^{-1}
\end{array}
$$

\section{Subscripts}

$\begin{array}{ll}G & \text { Gas } \\ l & \text { liquid } \\ p & \text { Particle } \\ r e f & \text { Reference properties } \\ { }_{\max } & \text { Maximal } \\ m & \text { Mixer }\end{array}$




\section{Caption of tables}

Table 1. Properties of the different liquids used in this study

Table 2. Comparison of the three junction geometries

\section{Caption of figures}

Figure 1. Illustration of the micro fluidic chip used to generate micro-bubble. From the left to the right, T-junction $\left(180^{\circ}\right)$, Y-junction $\left(90^{\circ}\right.$ and $\left.60^{\circ}\right)$.

Figure 2. Micro Particle Image Velocimetry principle ( $\mu$-PIV). $50 \times 50 \mu \mathrm{m}$ windows.

Figure 3. Bubble formation in a $\mathrm{T}$ micro-mixer. $\mathrm{V}_{\mathrm{b}}=0.8 \times 10^{-9} \mathrm{~m}^{3}$. Channel size is $500 \mu \mathrm{m}$, the liquid is pure water, liquid and gas flow rate are $10^{-8} \mathrm{~m}^{3} \cdot \mathrm{s}^{-1}$

Figure 4. Comparison of the formation of a $10^{-9} \mathrm{~m}^{3}$ bubble in two different micro-mixers.

Figure 5. Velocity Flow fields while the formation of a bubble in a $\mathrm{Y}$ section $(800 \mu \mathrm{m}) \mathrm{Q}_{\mathrm{L}}=$ $10^{-7} \mathrm{~m}^{3} / \mathrm{s}\left(\mathrm{v}_{\mathrm{L}}=0.2 \mathrm{~m} / \mathrm{s}\right)$. Liquid is water $+\operatorname{SDS} 0,15 \% . \sigma=40 \mathrm{mN} / \mathrm{m}$

Figure 6. Variation of the distance of breakup in function of flow rates ratio $Q_{G} / Q_{L}$.

Figure 7. Influence of the liquid physical properties and micro-mixer geometry. Channel size of 500, 800 and $1000 \mu \mathrm{m}$. (a) Influence of junction angle mixer $\theta_{\text {mixer }}$. (b) Influence of Surface tension.

Figure 8. Parity diagram between correlated data and experimental results. 


\section{Literature Cited}

Francois J., N. Dietrich, P. Guiraud, A. Cockx 2011, Direct measurement of mass transfer around a single bubble by micro-PLIFI, Chemical Engineering Science, 66 3328-3338

Dietrich N., Poncin S., H.-Z. Li Dynamical deformation of a flat liquid-liquid interface 2011 Experiments In Fluids 50(5) 1293-1303

Marupatch J.; Loubiere K.; Dietrich N.; G. Hebrard , Experimental study of oxygen diffusion coefficients in clean water containing salt, glucose or surfactant: Consequences on the liquidside mass transfer coefficients 2010 Chemical Engineering Journal 165-3, 758-768

Dietrich N., Poncin S., Pheulpin S., H.-Z. Li, Passage of a bubble through a liquid-liquid interface, AICHE JOURNAL, 54-3, 594-600

Funfschilling D., Debas H., Li H.Z. and Mason T., Flow-field dynamics during droplet formation by dripping in hydrodynamic-focusing microfluidics 2009, Phys. Review E, 80, 01530

Utada A. S, A. Fernandez-Nieves, H. A. Stone and D. A. Weitz, Dripping to jetting transitions in coflowing liquid streams 2007, Phys. Rev. Lett., 99(9), 094502

Van Steijn, V., Kleijn, C. R., \& Kreutzer, M. T. Flows around confined bubbles and their importance in triggering pinch-off 2009. Physical Review Letters, 103(21), 214501.

Utada AS, Fernandez-Nieves A, Stone HA, Weitz DA, Dripping to jetting transitions in coflowing liquid streams 2007 . Phys Rev Lett. 99(9):094502

Utada AS, Fernandez-Nieves A, Gordillo JM, Weitz DA, Absolute instability of a liquid jet in a coflowing stream 2008.Phys Rev Lett. 100(1):014502.

Fries DM, Rudolf von Rohr P. Impact of inlet design on mass transfer in gas-liquid rectangular microchannels. Microfluid Nanofluid. 2008, 6(1):27-35.

Baroud CN, Gallaire F, Dangla R. Dynamics of microfluidic droplets 2010. Lab Chip, 10(16):2032-2045.

Christopher GF, Anna SL. Microfluidic methods for generating continuous droplet streams 2007. J. Phys. D: Appl. Phys. 40(19):R319-R336.

Dollet B, van Hoeve W, Raven J-P, Marmottant P, Versluis M. Role of the Channel Geometry on the Bubble Pinch-Off in Flow-Focusing Devices 2008. Phys. Rev. Lett. 100(3).

van Steijn V, Kleijn CR, Kreutzer MT. Predictive model for the size of bubbles and droplets created in microfluidic T-junctions 2010. Lab Chip, 10(19):2513. 
[1] Wu J, Lu Z Y, Hu J C, Feng L, Huang J D, and Gu X S 2006 Disruption of granules by hydrodynamic force in internal circulation anaerobic reactors Water Science and Technology 54 9-16

[2] Frank X, Dietrich N, Wu J, Barraud R and Li H Z 2007 Chemical Engineering Science 62 7090-7097

[3] Garstecki P, Fuerstman M J, Stone H A and Whitesides GM 2006 Formation of droplets and bubbles in a microfluidic T-junction - scaling and mechanism of break up Lab on chip 6 437-446

[4] Chambers R D, Holling D, Spink R C H and Sandford G 2001 Elemental fluorine Part 13 Gas-liquid thin film microreactors for selective direct fluorination $L a b$ on Chip 1 132-137

[5] Kobayashi J, Mori Y, Okamoto K, Akiyama R, Ueno M, Kitamori T, and Kobayashi S A 2004 Microfluidic Device for Conducting Gas-Liquid-Solid Hydrogenation Reactions Science 304 1305-1308

[6] Burns M A, Johnson B N, Brahmasandra S N, James K H, Webster R, Krishnan M, Sammarco T S, Man P M, Jones D, Heldsinger D, Mastrangelo C H, and Burke D T 1998 An Integrated Nanoliter DNA Analysis Device Science 282 484-487

[7] Yen B K H, Gunther A, Schmidt M A and Jensen K F A 2005 Microfabricated GasLiquid Segmented Flow Reactor for High-Temperature Synthesis: The Case of CdSe Quantum Dots Angewandte Chemie International 44 5447-5451

[8] Zhang H, Tumarkin E, Peerani R, Nie Z, Sullan R M A, Walker G C and Kumacheva E 2006 Microfluidic production of biopolymer microcapsules with controlled morphology Journal of the American Chemical Society 128 1220512210

[9] Hettiarachchi K E, Talu M L, Longo P, Dayton A and Lee A P 2007 On-chip generation of microbubbles as a practical technology for manufacturing contrast agents for ultrasonic imaging Lab Chip 7 7407-416

[10] Talu E, Hettiarachchi K, Powell R L 2008 Maintaining Monodispersity in a Microbubble Population Formed by Flow Focusing Langmuir 245 1745-1749

[11] Talu E, Lozano M M and Powell R L 2006 Long-term Stability by Lipid Coating Monodisperse Microbubbles Formed by a Flow Focusing Device Langmuir 22 9487-9490

[12] Dittrich P S and Manz A 2006 Lab-on-a-chip: microfluidics in drug discovery A Nature Reviews Drug Discovery 5 210-218

[13] Waelchli S and von Rohr R 2006 Two-phase flow characteristics in gas-liquid micro reactors International Journal of Multiphase Flow 32 791-806

[14] Cubaud T and Ho C 2004 Transport of bubbles in square microchannels M Physics of Fluids 16 4575-4585

[15] Haverkamp V, Hessel V, Lowe H, Menges G, Warnier M J F, Rebrov E V, de Croon M H J M, Schouten J C and Liauw M A 2006 Hydrodynamics and mixerinduced bubble formation in micro bubble columns with single and multiplechannels Chemical Engineering Technology 29 1015-1026

[16] van der Graaf S, Nisisako T, Schroe C G P H, van der Sman R G M and Boom R M 2006 Lattice Boltzmann simulations of droplet formation in a T-shaped microchannel Langmuir 22 4144-4152

[17] Guillot P and Colin A 2005 Stability of parallel flows in a microchannel after a Tjunction Physical Review E 72066301

[18] Nisisako T, Torii T and Higuchi T 2002 Droplet formation in a microchannel network Lab on a Chip 2 24-26 
[19] Thorsen T, Roberts W R, Arnold F H and Quake S R 2001 Dynamic pattern formation in a vesicle-generating microfluidic device Physical Review Letters $\mathbf{8 6}$ 4163-4166

[20] Tice J D, Song H and Lyon A D, Ismagilov R F 2003 Formation of Droplets and Mixing in Multiphase Microfluidics at Low Values of the Reynolds and the Capillary Numbers Langmuir 19 9127-9133

[21] Xu J H, Li S W, Wang Y J and Luo G S 2006Controllable gas-liquid phase flow patterns and monodisperse microbubbles in a microfluidic $\mathrm{T}$-junction device Applied Physics Letters $\mathbf{8 8} 133506$

[22] Anna S L, Bontoux N, and Stone H A 2003 Formation of dispersions using "flow focusing" in microchannels Applied Physics Letters 82 364-366

[23] Cubaud T, Tatineni M, Zhong X, and Ho C M 2005 Bubble dispenser in microfluidic devices Physical Review E 27037302

[24] Ganan-Calvo A M and Gordillo J M 2001 Perfectly monodisperse microbubbling by capillary flow focusing Physical Review Letters $\mathbf{8 7} 274501$

[25] Garstecki P, Stone H A and Whitesides G M 2005 Mechanism for flow rate controlled breakup in confined geometries Phys Rev Lett 94164501

[26] Lindken R, Westerweel J and Wieneke B 2006 Stereoscopic micro particle image velocimetry Experiments in Fluids 11 161-171

[27] Thulasidas T C, Abraham M A and Cerro R L 1997 Flow patterns in liquid slugs during bubble train flow in capillaries Chemical Engineering Science 52 2947-2962

[28] Xiong R, Bai M and Chung J N 2007 Formation of bubbles in a simple co-flowing micro-channel Journal of Micromechanics and Microengineering 17 1002-1011

[29] van Steijn V, Kreutzer M T and Kleijn C R $2007 \mu$-PIV study of the formation of segmented flow in microfluidic T-junctions Chemical Engineering Science 62 7505-7514

[30] Dietrich N, Poncin S and Li H Z 2007 Dynamique des bulles dans un microréacteur Récents Progrès en Génie des Procédés n 95 Ed SFGP Paris France

[31] Dietrich N, Poncin S, Midoux N and Li H Z 2008 Bubble Formation Dynamics in Various Flow-Focusing Microdevices Langmuir 2413901

[32] Gañán-Calvo A M 1998 Generation of steady liquid microthreads and micron-sized monodisperse sprays in gas streams Physical Review Letters 80 285-288

[33] Fan L S, Yu Z and Hemminger O 2007 Experiment and lattice Boltzmann simulation of two phase gas-liquid flows in microchannels Chemical Engineering Science 62 7505-7514

[34] Einstein A 1905 Ann d Physik 17 549-560 (also demonstrated by Sutherland W 1905 Phil Mag 9 781)

[35] Brown R Edinburgh New Phil J 1928

[36] Cabral J T and Hudson S D 2006 Microfluidic approach for rapid multicomponent interfacial tensiometry Lab Chip $\mathbf{6} 427$ 